\title{
Photocatalytic Water-Splitting Reaction from Catalytic and Kinetic Perspectives
}

\author{
Takashi Hisatomi $\cdot$ Kazuhiro Takanabe • \\ Kazunari Domen
}

Received: 30 September 2014/ Accepted: 6 October 2014/Published online: 16 October 2014

(c) Springer Science+Business Media New York 2014

\begin{abstract}
Some particulate semiconductors loaded with nanoparticulate catalysts exhibit photocatalytic activity for the water-splitting reaction. The photocatalysis is distinct from the thermal catalysis because photocatalysis involves photophysical processes in particulate semiconductors. This review article presents a brief introduction to photocatalysis, followed by kinetic aspects of the photocatalytic water-splitting reaction.
\end{abstract}

Keywords Photocatalyst - Solar energy ·

Semiconductor · Water splitting · Hydrogen · Hydrogen evolution reaction (HER) - Oxygen evolution reaction (OER)

\section{Introduction to Photocatalytic Water Splitting}

Photocatalytic reactions differ from thermocatalytic reactions in many ways. Photocatalysis involves photophysical processes, which are initiated by photon absorption to generate excited states (new chemical potentials). This process is followed by photochemical or electrochemical redox reactions. These processes involve excited states with finite lifetimes, which determines the efficiency of the system and differentiates photocatalysis from conventional

T. Hisatomi $\cdot$ K. Domen $(\bowtie)$

Department of Chemical System Engineering, The University of Tokyo, 7-3-1 Hongo, Bunkyo-ku, Tokyo 113-8656, Japan e-mail: domen@chemsys.t.u-tokyo.ac.jp

\section{K. Takanabe}

Division of Physical Sciences and Engineering, KAUST Catalysis Center (KCC), King Abdullah University of Science and Technology (KAUST), 4700 KAUST, Thuwal 23955-6900, Saudi Arabia thermal catalytic reactions. Importantly, by utilizing excited states generated from photon energy, reactions that are energetically prohibitive under given reaction conditions (e.g., at room temperature) can be achieved in photocatalytic reactions. That is, some of the photon energy can be harvested as chemical energy as a result of the formation of photocatalytic products. This ability is the principal reason why photocatalysis has attracted growing interest in terms of solar energy conversion technology. Because the solar energy irradiating the surface of the Earth $\left(1.3 \times 10^{5} \mathrm{TW}\right)$ exceeds the current global human energy consumption $\left(1.6 \times 10^{1} \mathrm{TW}\right.$ in 2010 [1]) by approximately four orders of magnitude, efficient photocatalytic solar energy conversion on a large scale should have a significant impact on energy and environmental issues as well as the economy, as described later.

Figure 1 shows a simplified schematic of the reaction processes involved in overall water splitting using a single particulate photocatalyst [2]. Excited electrons and holes are generated in the bulk of the semiconductor photocatalyst particles upon band gap excitation. Photoexcited carriers with opposite signs are separated and transferred to surface active sites by either diffusion or electric fields associated with the semiconductor-electrolyte and semiconductor-cocatalyst interfaces. The photocatalysis then culminates in surface electrochemical redox reactions, wherein electrons and holes must be consumed at the same rate. The adsorption, desorption and mass transport of reactants and products should proceed effectively. However, the majority of photoexcited carriers are often lost by carrier recombination, which occurs largely in the bulk of the semiconductor, generating either heat or photoluminescence. The photocatalytic efficiency (i.e., photocatalytic rate) is determined by a multiplication of the efficiencies of these consecutive processes. Therefore, a specific reaction 


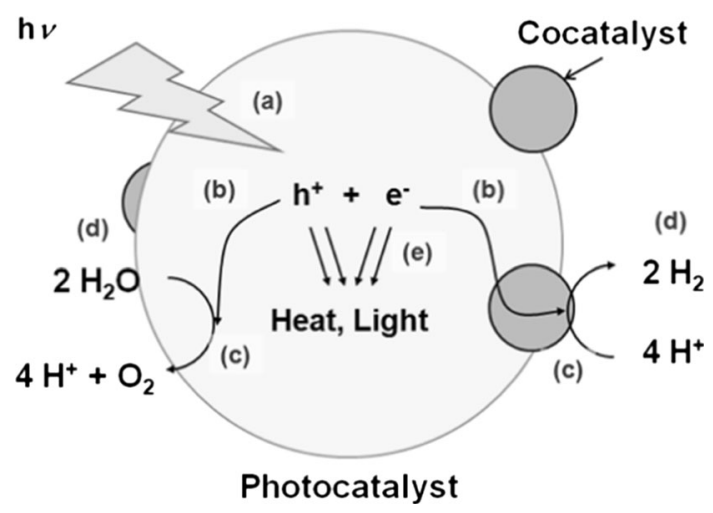

Fig. 1 Reaction processes of water splitting on a heterogeneous photocatalyst. (a) Light absorption, (b) charge transfer, (c) redox reactions, $(d)$ adsorption, desorption and mass diffusion of chemical species, and $(e)$ charge recombination. Reprinted with permission from Ref. [2]. Copyright (C) 2012 The Chemical Society of Japan

step cannot be assigned as rate determining in the same manner as in thermal catalytic reactions. It is often difficult to identify the key aspect for improving the photocatalytic activity.

This review article mainly focuses on the reaction kinetics involved in the photocatalytic overall water-splitting reaction. After a general introduction to photocatalytic water splitting, the timescales of the photophysical processes are discussed. Next, the importance of cocatalysts in electrocatalytic reactions is discussed. A list of photocatalysts that are able to split water into hydrogen and oxygen is provided, and literature data on electrocatalytic performance and its correlation with photocatalytic activity are presented. Some unique structures of cocatalysts that effectively suppress unfavorable side reactions, such as water formation from water-splitting products (back reaction), are discussed. The effects of coloading hydrogen evolution catalysts and oxygen evolution catalysts are then described. Furthermore, the effects of light intensity, hydrogen/deuterium isotopes, and reaction temperature (thermal activation energy) on the rates of the photocatalytic water-splitting reaction are reviewed to understand kinetic aspects that are unique to photocatalysis. Finally, the review concludes with some future perspectives.

\section{Definition of Photocatalytic Efficiency}

The activities of photocatalysts are often reported as gas evolution rates in photocatalytic water splitting with various light sources for convenience. However, it is extremely difficult to compare the activities measured in different reaction systems because of differences in the photocatalytic reactor systems and in the irradiance of different light sources. Thus, a measure of photocatalytic performance that is independent of the reactor and light source used is needed. In practice, the extent of photon absorption by a photocatalyst in a reactor is difficult to capture quantitatively. Assuming that the photons illuminated in the reactor are effectively used for absorption, the amount of products divided by the amount of incident photons at a given wavelength, i.e., the apparent quantum yield (AQY) or apparent quantum efficiency (AQE), can be used as a standard measure of activity. The AQY must be determined for a given photon energy and is defined as

$\operatorname{AQY}(h v)=\frac{n R}{I}$,

where $n, R$, and $I$ denote the number of electrons involved in the photocatalytic reaction, the molecular production rate, and the rate of incident photons, respectively. In overall water splitting using a single photocatalyst, the values of $n$ for the hydrogen and oxygen evolution are two and four, respectively, whereas the evolution rate $R$ for hydrogen is stoichiometrically twice that for oxygen. Thus, the AQY values from hydrogen and oxygen evolution are identical. AQY is dependent on the photon wavelength, which typically decreases as the irradiation wavelength approaches the absorption edge because of the lower absorption coefficients and longer migration distances for photoexcited carriers. Therefore, the determination of AQY requires monochromatic irradiation. Importantly, AQY generally depends on the light intensity. A number of previous studies have reported that AQY decreases with increasing light intensity because charge recombination is a second-order reaction with respect to light intensity in the high-intensity region [2]. If the dependence of AQY on photon irradiance is measured over a wide range of wavelengths using monochromatic light, the photocatalytic rates can be obtained for any light source power spectrum. Overall, reporting AQY with the intensity and distribution (photon spectrum) of the incident light is highly recommended.

Unlike thermal catalytic reactions, photocatalytic rates are not reported per photocatalyst mass used unless the goal is to optimize the performance of a specific photocatalytic reactor. The photocatalytic rates are not proportional to the photocatalyst mass because light absorption reaches saturation at some point. AQY should accordingly be measured when the amount of photocatalyst is sufficient and the incident light is effectively absorbed by the photocatalysts. If the photocatalytic rates increase with an increasing amount of photocatalyst, the measured rates are not a measure of photonic efficiency but simply a reactorspecific reflection of the amount of photocatalyst. Photocatalytic activity, including AQY and the effectiveness of charge separation, must be compared based on the 
absorbed photons, which must not depend on the amount of photocatalyst present in the photoreactor.

When solar energy conversion is of interest, a simulated solar spectrum can be used as incident light (using the entire spectrum rather than monochromatic light). The benchmark efficiency for solar hydrogen production via water splitting and the diagnostic efficiencies for the investigation of material performance were recently reviewed [3, 4]. The solar-to-hydrogen efficiency (STH) can be calculated from the product of the hydrogen production rate $\left(r_{\mathrm{H} 2}\right)$ and an increase in the Gibbs free energy $(\Delta G)$ of $237 \mathrm{~kJ} \mathrm{~mol}^{-1}$ :

$\mathrm{STH}=\frac{\text { output energy }}{\text { Energy of incidence solar light }}=\frac{r_{\mathrm{H}_{2}} \times \Delta G}{P_{\mathrm{Sun}} \times S}$,

where $P_{\text {sun }}$ is the energy flux of sunlight and $S$ is the area of the reactor. ASTM-G173 AM 1.5 global tilt is commonly used as the standard solar irradiation, with an energy flux of $1.0 \times 10^{3} \mathrm{~W} \mathrm{~m}^{-2}$ and a well-defined power spectrum. STH is an absolute and practical standard for the performance of photocatalysts under sunlight. It is recommended that the irradiance (photon number as a function of wavelength) used for the measurement be reported with the STH values for clarity.

A techno-economical analysis of the commercial value of hydrogen produced in various photocatalytic and photoelectrochemical systems was recently reported [5]. Given an STH of $10 \%$ and a lifetime of ten years for a particulate photocatalyst, the price of hydrogen was estimated to be $1.6 \mathrm{USD} \mathrm{kg}^{-1}$, which could meet the target hydrogen price of 2-4 USD kg-1 $\left(0.18-0.36 \mathrm{USD} \mathrm{Nm}^{-3}\right)$ suggested by the United States Department of Energy. Particulate photocatalytic systems suffer from difficulty in improving the STH and safe separation of the hydrogen and oxygen produced, although particulate systems with unique plastic baggie reactors were considered less expensive than relevant photoelectrochemical systems in the report. STH values of $5 \%$ or higher could be regarded as a requirement for the practical operation of photocatalytic solar hydrogen plants. One might wonder what requirements the photocatalysts should meet to achieve 5 and $10 \%$ STH. To answer this question, Fig. 2 presents the relationship between STH and the wavelengths of photons available in AM 1.5 at different AQYs for photocatalytic water splitting. AQYs of 62,40 , and $30 \%$ are needed to achieve $10 \%$ STH when using solar photons with wavelengths shorter than 600,700 , and $800 \mathrm{~nm}$, respectively, at the constant AQYs. The STH of a photocatalyst that absorbs only UV light $(\lambda<400 \mathrm{~nm})$ is limited to $1.7 \%$ even if the AQY is unity because of the limited number of photons in the UV range and the dissipation of more than half of the energy of the UV photons as heat while producing $\mathrm{H}_{2}$. Thus, it is necessary to develop and activate narrow-band-

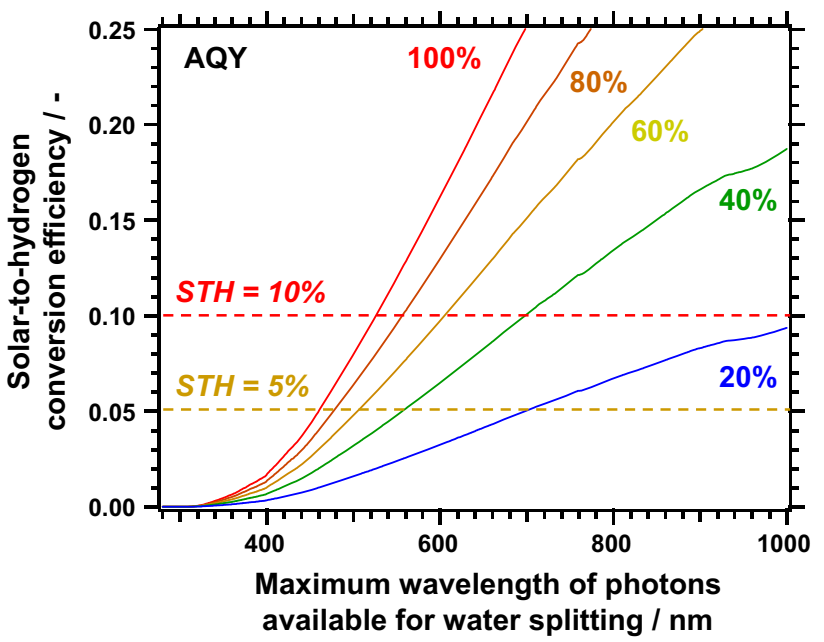

Fig. 2 Relationship between STH and photon wavelengths available at different AQYs for photocatalytic water splitting. It is assumed that two water molecules are split into two hydrogen molecules and one oxygen molecule in four-photon processes

gap semiconducting photocatalysts for practical operation despite the present low activity of photocatalysts with absorption edge wavelengths longer than $600 \mathrm{~nm}$ for the overall water-splitting reaction. Solar hydrogen plants with areas of $25 \mathrm{~km}^{2}$ consisting of photocatalysts with $10 \%$ STH and incidental equipment for gas separation and purification can generate 570 tons of hydrogen from 5,100 tons of water daily [6]. Hydrogen may be converted into liquid fuels, such as methanol or methylcyclohexane, for easy transportation and storage by catalytic processes. Approximately 10,000 such solar hydrogen plants $\left(250,000 \mathrm{~km}^{2}\right)$ are needed to provide one-third of the projected energy needs of human society in 2050 from solar energy. Therefore, photocatalytic systems must be designed bearing scalability in mind.

\section{Energy Diagram}

A semiconductor photocatalyst has a forbidden band (band gap) between the conduction band and valence band. When a photocatalyst absorbs photons with energies higher than its band gap energy, the electrons in the valence band are excited into the conduction band, leaving positive holes in the valence band. For efficient photocatalysis, this electron-hole pair (exciton) must be separated, and both the excited electron and excited hole should travel to the respective surfaces. These photogenerated carriers can drive reduction (electrons) and oxidation (holes) reactions when the charge injections are thermodynamically favorable. To achieve an overall water-splitting reaction, the band gap of a semiconductor must straddle the reduction 


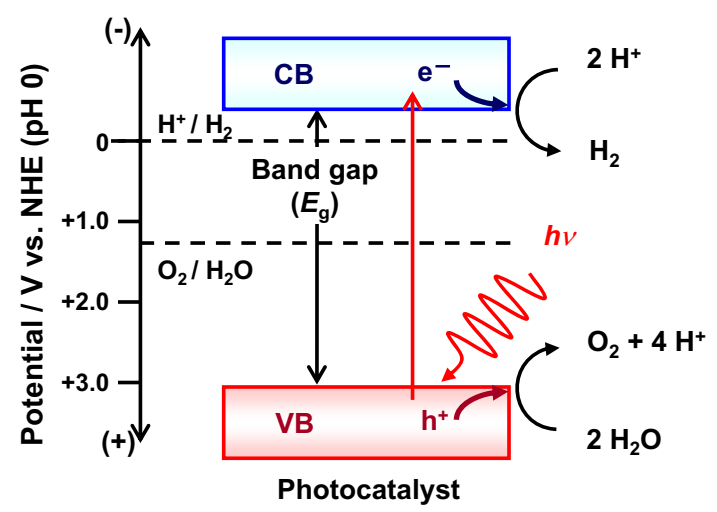

Fig. 3 Energy diagrams of photocatalytic water splitting. Adapted with permission from Ref. [4]. (C) The Royal Society of Chemistry 2014

and oxidation potentials of water, which are +0 and $+1.23 \mathrm{~V}$, respectively, versus a reversible hydrogen electrode (RHE) at a given pH, as shown in Fig. 3 [4]. Charge separation in photocatalyst particles must proceed within the timescales of photoexcited carrier recombinations to drive efficient water splitting. The photocatalyst particles are often modified with noble metal or metal oxide nanoparticles (cocatalysts) [7-9]. The cocatalysts facilitate charge separation by creating new cocatalyst-semiconductor interfaces, which extends the lifetime of photoexcited carriers and enhances electrocatalytic activity, minimizing the overpotential of the water redox reactions.

\section{Timescale of Photocatalysis}

The dynamics of photoexcited carriers in nanoparticulate $\mathrm{TiO}_{2}[10-13]$ and $\mathrm{CdS}[14,15]$ have been studied in detail using transient absorption spectroscopy. In the case of $\mathrm{TiO}_{2}$, surface-trapped electrons and holes are generated within $200 \mathrm{fs}$ after photoexcitation [10]. Surface-trapped and bulk electrons equilibrate and relax into deep trap sites with a time constant of a few hundred picoseconds [10]. Photoexcited electrons react with gaseous $\mathrm{O}_{2}$ within $10-100 \mu$ s [11], whereas surface-trapped holes react with methanol, ethanol, and 2-propanol within 300, 1000, and $3000 \mathrm{ps}$, respectively [12]. It is necessary to load a cocatalyst on a photocatalyst to enhance the $\mathrm{H}_{2}$ evolution reaction (HER). Although the timescale of electron transfer from $\mathrm{TiO}_{2}$ particles to cocatalysts is unknown, electrons reduce water in 10-900 $\mu$ s on platinized $\mathrm{TiO}_{2}$ [11], indicating that the electron transfer occurs within this timescale. For comparison, photoexcited electrons in an $\mathrm{NaTaO}_{3}$ photocatalyst migrate to an $\mathrm{NiO}$ cocatalyst within $1 \mu \mathrm{s}$ after excitation [7]. In contrast, photoexcited holes in
$\mathrm{TiO}_{2}$ can oxidize water on the timescale of microseconds to seconds $[11,16]$. Thus, the surface redox reactions of photocatalytic water splitting take microseconds or longer. Bulk processes, such as light absorption by photocatalysts and charge migration to surface active sites, proceed faster than surface redox reactions. Under weak light irradiation, wherein only a single electron-hole pair is generated in a $\mathrm{TiO}_{2}$ particle, recombination of photoexcited electrons and holes occurs on the microsecond timescale in the absence of effective electron and hole scavengers [10]. It has also been reported that more than $90 \%$ of photoexcited carriers are recombined in $10 \mathrm{~ns}$ [13]. Although the rate of charge recombination depends strongly on the physical properties of a material and excitation density, charge recombination clearly competes with the water-splitting reaction and restricts the quantum efficiency for photocatalytic overall water splitting to low values. Photocatalytic reactions proceed efficiently in the presence of appropriate electron or hole scavengers [17] because such additives rapidly consume the respective photoexcited carrier and effectively prevent charge recombination.

\section{Electrocatalytic Hydrogen and Oxygen Evolution Reactions}

It is generally accepted that the rate-determining steps of the electrochemical HER are bond cleavage and formation involving $\mathrm{H}$ atoms. In acidic solutions, the reaction paths can be expressed as follows:

$\mathrm{M}+\mathrm{H}_{3} \mathrm{O}^{+}+\mathrm{e}^{-} \rightleftarrows \mathrm{M}-\mathrm{H}_{\text {ads }}+\mathrm{H}_{2} \mathrm{O}$

$\mathrm{M}-\mathrm{H}_{\mathrm{ads}}+\mathrm{H}_{3} \mathrm{O}^{+}+\mathrm{e}^{-} \rightleftarrows \mathrm{M}+\mathrm{H}_{2}+\mathrm{H}_{2} \mathrm{O}$

$\mathrm{M}-\mathrm{H}_{\mathrm{ads}}+\mathrm{M}-\mathrm{H}_{\mathrm{ads}} \rightleftarrows 2 \mathrm{M}+\mathrm{H}_{2}$

where $\mathrm{M}$ represents an atom of the metal electrode. Equations (3)-(5) are known as the Volmer (electrochemical discharge), Heyrovsky (electrochemical desorption), and Tafel (catalytic desorption) reactions, respectively. The kinetic isotope effect and apparent activation energy for electrochemical HER should be unique to the type of metal electrode and rate-determining step [18-20] because of variations in the energies of hydrogen (deuterium) bond stretching, zero-point energies and tunneling probabilities of the isotopes. Furthermore, the reorganization of polar media and involvement of exited vibrational states are suggested to have a significant influence on the proton (deuteron) tunneling probability [21, 22]. However, the kinetic parameters are sensitive to the crystal plane [19], electrode geometry and applied voltage [23], and the kinetic mechanisms remain under debate [24, 25].

Electrochemical $\mathrm{O}_{2}$ evolution reactions (OERs) have been studied using density functional theory calculations 
[26-28]. However, the primary reaction steps have not been identified experimentally in an unambiguous manner because of the instability of the electrode surface at the oxygen evolution potentials and the difficulty of identifying the reaction intermediates. Considering only the surface species, the four electron reaction paths are assumed to be as follows [28]:

$$
\begin{aligned}
& \mathrm{H}_{2} \mathrm{O}+{ }^{*} \rightleftarrows \mathrm{HO}^{*}+\mathrm{H}^{+}+\mathrm{e}^{-} \\
& \mathrm{HO}^{*} \rightleftarrows \mathrm{O}^{*}+\mathrm{H}^{+}+\mathrm{e}^{-} \\
& \mathrm{O}^{*}+\mathrm{H}_{2} \mathrm{O} \rightleftarrows \mathrm{HOO}^{*}+\mathrm{H}^{+}+\mathrm{e}^{-} \\
& \mathrm{HOO}^{*} \rightleftarrows{ }^{*}+\mathrm{O}_{2}(\mathrm{~g})+\mathrm{H}^{+}+\mathrm{e}^{-}
\end{aligned}
$$

DFT calculations revealed that there is a constant difference between the adsorption energies of $\mathrm{HO}^{*}$ and $\mathrm{HOO}^{*}$ regardless of the binding energy of $\mathrm{O}^{*}$ [28]. The variation in the overpotential is closely related to the $\mathrm{O}^{*}$ adsorption energy, for which Eq. (7) or (8) represents the potentialdetermining step. Theoretical calculations give the following activity order for the binary oxides considered: $\mathrm{Co}_{3} \mathrm{O}_{4} \approx \mathrm{RuO}_{2}>\mathrm{PtO}_{2}$-rutile phase $\approx \mathrm{RhO}_{2}>\mathrm{IrO}_{2} \approx$ $\mathrm{PtO}_{2} \beta$-phase $\left(\mathrm{CaCl}_{2}\right) \approx \mathrm{Mn}_{x} \mathrm{O}_{y} \approx \mathrm{NiO} \approx \mathrm{RuO}_{2}$. This trend corresponds well with the experimental findings of Matsumoto and Sato for alkaline conditions [29]. The investigation of photocatalytic and photoelectrochemical methods for oxygen evolution utilizes the oxide forms of Co [30], Ru [31], Mn [9, 31], and Ir [31, 32]. The theoretical analysis predicted the following ordering of catalytic activities for the following perovskite-type oxides: $\mathrm{SrCoO}_{3}>\mathrm{LaNiO}_{3}>\mathrm{SrNiO}_{3}>\mathrm{SrFeO}_{3}>\mathrm{LaCoO}_{3}>\mathrm{La}-$ $\mathrm{FeO}_{3}>\mathrm{LaMnO}_{3}$. This trend corresponds well with experimental findings by Bockris et al. and Matsumoto et al. [29, 33] under alkaline conditions. More recently, some double perovskite-type oxides, such as $\mathrm{Ba}_{0.5} \mathrm{Sr}_{0.5}$ $\mathrm{Co}_{0.8} \mathrm{Fe}_{0.2} \mathrm{O}_{3-\delta}$ [34] and $\left(\mathrm{Ln}_{0.5} \mathrm{Ba}_{0.5}\right) \mathrm{CoO}_{3-\delta}$ ( $\mathrm{Ln}=\mathrm{Pr}, \mathrm{Sm}$, $\mathrm{Gd}$ and $\mathrm{Ho}$ ) [35], were reported as highly active catalysts for oxygen evolution in alkaline conditions, the latter being more active and robust during the reaction. The intrinsic OER activity exhibits a volcano-shaped dependence on the occupancy of the $3 \mathrm{~d}$ electron with an $\mathrm{e}_{\mathrm{g}}$ symmetry of surface transition metal cations in an oxide. It was concluded that a near-unity occupancy of the $e_{g}$ orbital of surface transition metal ions and high covalency in bonding to oxygen led to the peak OER activity [34]. However, the above two descriptors inevitably suffer from ambiguities when the central ions can have multiple crystal fields, oxidation states, and/or spin states. Subsequently, the computed $\mathrm{O}$ p-band center relative to the Fermi level and the derived parameters were suggested as descriptors to screen the OER activity and stability of oxides [35]. Moving the computed O p-band center closer to the Fermi level can increase the OER activity, but the oxide stability during OER is decreased if the computed $\mathrm{O}$ p-band center is sufficiently close to the Fermi level. The $\mathrm{O}$ p-band of $\mathrm{Ba}_{0.5} \mathrm{Sr}_{0.5} \mathrm{Co}_{0.8} \mathrm{Fe}_{0.2} \mathrm{O}_{3-\delta}$ was overly close to the Fermi level, causing the amorphization of the material during OER. $\left(\mathrm{Pr}_{0.5} \mathrm{Ba}_{0.5}\right) \mathrm{CoO}_{3}$ produced the best activity and durability among the double perovskite-type cobalt oxides examined. The above findings will facilitate the development of efficient cocatalysts for oxygen evolution in photocatalytic systems for water splitting. The redox properties of the cocatalysts may endow the intermediate states with extended lifetimes, enhancing the charge separation.

\section{History of Photocatalytic Overall Water Splitting}

\subsection{UV-Responsive Photocatalysts}

A number of studies have found a series of transition metal oxides with a $\mathrm{d}^{0}$ electronic configuration and typical metal oxides with a $\mathrm{d}^{10}$ electronic configuration that are active for photocatalytic water splitting under UV light illumination. $\mathrm{TiO}_{2}$ [36] and $\mathrm{SrTiO}_{3}[37,38]$ modified with cocatalysts were reported in 1980 as the first reliable materials with photocatalytic overall water-splitting activity. Loading appropriate catalysts is often essential to achieve the overall water-splitting reaction at appreciable rates. For example, the photocatalytic activity of unmodified $\mathrm{SrTiO}_{3}$ for overall water splitting is negligible because of a lack of hydrogen evolution sites [39]. In fact, most oxide photocatalysts exhibit an n-type character, readily accumulating excited holes on their surfaces, and the structure of the oxide surface typically has high OER activity. In this case, the generated excited electrons prefer to stay in the bulk of the semiconductor; as a result, metal nanoparticles can often effectively transport such electrons to the surface by guiding them along the metal-semiconductor interface [40]. Additionally, the oxide surface lacks HER activity. Excellent HER catalysts, such as Pt, also function as good hydrogen evolution sites for photocatalysts; however, in reality, this approach is not effective for photocatalytic overall water splitting because Pt catalyzes the formation of water from hydrogen and oxygen mixtures, even without illumination. In the earliest studies [36, 37], water vapor was used as a reactant to wet the cocatalyst surface and slow the back reactions [36]. Other successful overall water-splitting reactions have used cocatalysts that were less active for water formation, such as $\mathrm{NiO}$ [37].

For photocatalytic water splitting, the rate of liquid water splitting is generally higher than that of water vapor splitting [41] because the activity of water is considered to be unity in liquid, and thus, adsorption does not limit the overall process. It was revealed that $\mathrm{Ni}$ cocatalysts, treated 


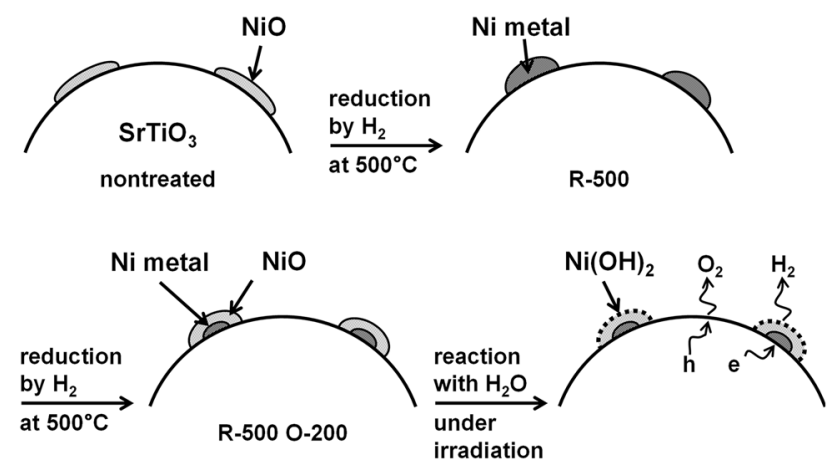

Fig. 4 Schematic of the structure of a $\mathrm{NiO} / \mathrm{SrTiO}_{3}$ photocatalyst after various treatments. Adapted with permission from ref [42], Copyright (C) 1986, American Chemical Society

first by reduction followed by mild oxidation, were effective for water splitting, and $\mathrm{Ni} / \mathrm{NiO}$ core/shell particles (Fig. 4) were proposed using a $\mathrm{SrTiO}_{3}$ photocatalyst [39, 42]. The formation of a core/shell structure was proposed based on the results of X-ray absorption spectroscopy (XAFS) and X-ray photoelectron spectroscopy (XPS). It was suggested that the $\mathrm{Ni} / \mathrm{NiO}$ core/shell produced the higher photocatalytic activity because the $\mathrm{Ni}$ metal between $\mathrm{NiO}$ and $\mathrm{SrTiO}_{3}$ facilitated electron transfer between the photocatalyst and cocatalyst. In contrast, it was recently reported that nickel species prepared using similar procedures on $\mathrm{SrTiO}_{3}$ consisted of a mixture of $\mathrm{Ni}$ and $\mathrm{NiO}$ nanoparticles [43]. Surface voltage spectroscopy, the photodeposition of Pt nanoparticles, and (photo) electrochemical measurements suggested that the nickel species contributed to both HER and OER. Ni nanoparticles serve as electron traps and lower the proton reduction overpotential, whereas $\mathrm{NiO}$ nanoparticles serve as hole traps and lower the water oxidation overpotential [43]. This view corresponds well with the conclusions of recent works on the coloading of cocatalysts for hydrogen evolution and oxygen evolution, which have found that coloading appropriate amounts of oxygen evolution catalysts can improve the overall water-splitting rate $[9,31]$. The characterizations of nickel species as $\mathrm{Ni} / \mathrm{NiO}$ core/shell particles and as $\mathrm{Ni}-\mathrm{NiO}$ mixtures are self-consistent. The contrast in the characterization and interpretation may arise from the use of different types of $\mathrm{SrTiO}_{3}$ as supports and the different amounts and temperatures used for the loading and treatment of nickel species as cocatalysts.

$\mathrm{NaTaO}_{3}$ doped with $\mathrm{La}$ [44] and $\mathrm{Ga}_{2} \mathrm{O}_{3}$ doped with $\mathrm{Zn}$ [45] exhibit the highest known QY water-splitting rates under UV irradiation after successful catalyst loading with $\mathrm{NiO}$ and $\mathrm{Rh}_{2-y} \mathrm{Cr}_{y} \mathrm{O}_{3}$, respectively. Both $\mathrm{NiO}$ and $\mathrm{Rh}_{2-y}$ $\mathrm{Cr}_{y} \mathrm{O}_{3}$ cocatalysts improved hydrogen evolution activity, which is essential for achieving overall water splitting. In addition, transient absorption spectroscopy revealed that photoexcited electrons in the conduction band were quenched by the loading of the hydrogen evolution cocatalyst [7], indicating the successful charge separation of photoexcited electrons and holes by introducing cocatalysts. Similar results were reported for $\mathrm{TiO}_{2}$ modified with $\mathrm{Pt}$ [11]. Therefore, cocatalysts can facilitate both charge separation and surface kinetics, especially if an ohmic contact is formed at the photocatalyst-cocatalyst interface to facilitate the flow of electrons into the cocatalyst. Otherwise, the cocatalyst would also collect photoexcited holes and function as a recombination center.

\section{$6.2\left(\mathrm{Ga}_{1-x} \mathrm{Zn}_{x}\right)\left(\mathrm{N}_{1-x} \mathrm{O}_{x}\right)$ Photocatalyst}

Certain oxynitride photocatalysts can reproducibly achieve overall water splitting under visible light after modification with cocatalysts, such as $\mathrm{Rh}_{2-y} \mathrm{Cr}_{y} \mathrm{O}_{3}$. For example, $\left(\mathrm{Ga}_{1-x}\right.$ $\left.\mathrm{Zn}_{x}\right)\left(\mathrm{N}_{1-x} \mathrm{O}_{x}\right)$ and $\left(\mathrm{Zn}_{1+x} \mathrm{Ge}\right)\left(\mathrm{N}_{2} \mathrm{O}_{x}\right)$ loaded with appropriate hydrogen evolution cocatalysts can split water [46]. In particular, $\left(\mathrm{Ga}_{1-x} \mathrm{Zn}_{x}\right)\left(\mathrm{N}_{1-x} \mathrm{O}_{x}\right)$ modified with $\mathrm{Rh}_{2-y} \mathrm{Cr}_{y} \mathrm{O}_{3}$ has shown the highest AQY to date for overall water splitting using a single photocatalyst under visible light $(5.1 \%$ at $410 \mathrm{~nm}$ ) [6]. For cocatalyst loading, the presence of both $\mathrm{Rh}$ and $\mathrm{Cr}$ species is essential, with efficiency typically peaking at $1 \mathrm{wt} \% \mathrm{Rh}$ and $1.5 \mathrm{wt} \% \mathrm{Cr}_{2} \mathrm{O}_{3}$ [47]. The $\mathrm{Rh}_{2-y} \mathrm{Cr}_{y} \mathrm{O}_{3}$ cocatalyst, a mixed oxide of corundum-type $\mathrm{Rh}_{2} \mathrm{O}_{3}$ and $\mathrm{Cr}_{2} \mathrm{O}_{3}$, was typically $10-30 \mathrm{~nm}$ in size, although the composition varied among the particles [48]. An improvement in photocatalytic activity was found by coloading $\mathrm{Cr}$ species regardless of the type of metal, suggesting that $\mathrm{Cr}$ addition provides some general functionality for overall water splitting.

The use of a sacrificial electron donor (methanol) and an acceptor $\left(\mathrm{Ag}^{+}\right)$is useful for investigating whether a cocatalyst affects hydrogen or oxygen evolution sites. A good example is demonstrated for $\mathrm{Rh}_{2-y} \mathrm{Cr}_{y} \mathrm{O}_{3}$ cocatalysts on $\left(\mathrm{Ga}_{1-x} \mathrm{Zn}_{x}\right)\left(\mathrm{N}_{1-x} \mathrm{O}_{x}\right)$, as listed in Table 1 [49]. $\left(\mathrm{Ga}_{1-x}\right.$ $\left.\mathrm{Zn}_{x}\right)\left(\mathrm{N}_{1-x} \mathrm{O}_{x}\right)$ without cocatalyst loading exhibited no activity for the photocatalytic HER, even in the presence of an electron donor (methanol). Loading $\mathrm{Rh}_{2-y} \mathrm{Cr}_{y} \mathrm{O}_{3}$ enabled the production of hydrogen at a rate comparable to that for metallic $\mathrm{Rh}$ loading but considerably higher than that for $\mathrm{RuO}_{2}$ loading. In contrast, loading $\mathrm{Rh}_{2-y} \mathrm{Cr}_{y} \mathrm{O}_{3}$ slightly lowered the oxygen evolution activity, indicating that $\mathrm{Rh}_{2-y} \mathrm{Cr}_{y} \mathrm{O}_{3}$ did not enhance oxygen evolution, unlike $\mathrm{RuO}_{2}$. This experiment indicated that $\mathrm{Rh}_{2-y} \mathrm{Cr}_{y} \mathrm{O}_{3}$ functions as an efficient hydrogen evolution site. Another important feature of the $\mathrm{Rh}_{2-y} \mathrm{Cr}_{y} \mathrm{O}_{3}$ cocatalyst is its high selectivity for HER [49]. The water-splitting rate is significantly reduced in the presence of oxygen when $\mathrm{RuO}_{2}$ is used as a cocatalyst because the photoreduction of oxygen competes with $\mathrm{HER}$ on $\mathrm{RuO}_{2}$. In contrast, the water- 
Table 1 Photocatalytic activities of $\left(\mathrm{Ga}_{1-x} \mathrm{Zn}_{x}\right)\left(\mathrm{N}_{1-x} \mathrm{O}_{x}\right)$ in the presence of sacrificial reagents

\begin{tabular}{llll}
\hline Cocatalyst & Reaction solution & \multicolumn{2}{l}{ Activity $/ \mathrm{mmol} \mathrm{h}^{-1 \mathrm{a}}$} \\
\cline { 3 - 4 } & & $\mathrm{H}_{2}^{\mathrm{b}}$ & $\mathrm{O}_{2}^{\mathrm{c}}$ \\
\hline None & $10 \mathrm{vol} \% \mathrm{CH}_{3} \mathrm{OH}$ aq & 0 & - \\
$\mathrm{Rh}_{2-y} \mathrm{Cr}_{y} \mathrm{O}_{3}$ & $10 \mathrm{vol} \% \mathrm{CH}_{3} \mathrm{OH}$ aq & 0.36 & - \\
$\mathrm{RuO}_{2}$ & $10 \mathrm{vol} \% \mathrm{CH}_{3} \mathrm{OH}$ aq & 0.04 & - \\
$\mathrm{Rh}_{\mathrm{None}}$ & $10 \mathrm{vol} \% \mathrm{CH}_{3} \mathrm{OH}$ aq & 0.28 & - \\
$\mathrm{Rh}_{2-y} \mathrm{Cr}_{y} \mathrm{O}_{3}$ & $10 \mathrm{mM} \mathrm{AgNO}$ aq & - & 0.55 \\
$\mathrm{RuO}_{2}$ & $10 \mathrm{mM} \mathrm{AgNO} \mathrm{Aq}_{3} \mathrm{aq}$ & - & 0.31 \\
\hline
\end{tabular}

${ }^{a}$ Reaction conditions: catalyst $(0.3 \mathrm{~g})$; reaction solution $(370 \mathrm{~mL})$; light source: a $450 \mathrm{~W}$ high-pressure mercury lamp equipped with an aqueous $\mathrm{NaNO}_{2}$ solution filter $(\lambda>400 \mathrm{~nm})$

b Steady rate of gas evolution

c Initial rate of gas evolution. Reprinted from Ref. [49] with permission. Copyright (c) 2006, American Chemical Society

splitting rate for $\left(\mathrm{Ga}_{1-x} \mathrm{Zn}_{x}\right)\left(\mathrm{N}_{1-x} \mathrm{O}_{x}\right)$ modified with $\mathrm{Rh}_{2-y}$ $\mathrm{Cr}_{y} \mathrm{O}_{3}$ is largely independent of the partial pressure of oxygen in the reaction system. Therefore, the high selectivity of $\mathrm{Rh}_{2-y} \mathrm{Cr}_{y} \mathrm{O}_{3}$ for hydrogen evolution contributes to the high activity of $\mathrm{Rh}_{2-y} \mathrm{Cr}_{y} \mathrm{O}_{3} /\left(\mathrm{Ga}_{1-x} \mathrm{Zn}_{x}\right)\left(\mathrm{N}_{1-x} \mathrm{O}_{x}\right)$. Furthermore, the $\mathrm{Rh}_{2-y} \mathrm{Cr}_{y} \mathrm{O}_{3}$ cocatalyst is generally applicable to other photocatalysts [47].

As noted earlier, noble metal nanoparticles alone cannot be applied as a cocatalyst for overall water splitting because of their high rates of the back reaction, namely, the formation of water from hydrogen and oxygen via oxygen reduction. In an important breakthrough, the application of Cr-based species to cover the metal surfaces, creating a core/shell structure, was found to suppress the back reaction. Such core/shell-type nanocomposites can be deposited on $\left(\mathrm{Ga}_{1-x} \mathrm{Zn}_{x}\right)\left(\mathrm{N}_{1-x} \mathrm{O}_{x}\right)$ by sequential photodeposition [50]. After the first photodeposition of $\mathrm{Rh}$ nanoparticles, hexavalent chromium species, such as $\mathrm{K}_{2} \mathrm{CrO}_{4}$, were reductively photodeposited selectively on the metal species (as electrons are collected mainly on metals). The $\mathrm{Cr}$ shell ultimately featured an approximately 2-nm-thick chromium oxide shell. The resultant $\left(\mathrm{Ga}_{1-x} \mathrm{Zn}_{x}\right)\left(\mathrm{N}_{1-x} \mathrm{O}_{x}\right)$ modified with the $\mathrm{Rh} / \mathrm{Cr}_{2} \mathrm{O}_{3}$ core/shell cocatalyst exhibited photocatalytic activity for overall water splitting under visible light irradiation. Thus, a $\mathrm{Cr}_{2} \mathrm{O}_{3}$ shell can effectively prevent the backward reaction. Electrochemical analysis revealed that the $\mathrm{Cr}_{2} \mathrm{O}_{3}$ shell suppressed water formation on the $\mathrm{Rh}$ nanoparticles because of the selective permeability of the ultrathin hydrated chromia layer to protons and gaseous hydrogen [51]. Because oxygen molecules cannot access the Rh surface, the reductive side reactions involving oxygen molecules are negligible [51], as shown in Fig. 5.

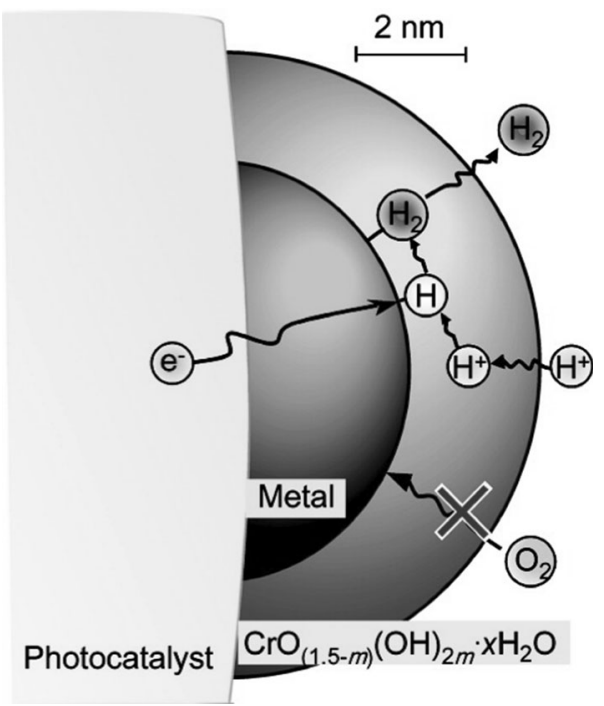

Fig. 5 Schematic model of the $\mathrm{H}_{2}$ evolution reaction on a core/shell noble-metal/ $\mathrm{Cr}_{2} \mathrm{O}_{3}$ cocatalyst particle for photocatalytic overall water splitting. Reprinted from Ref. [51] with permission. Copyright (C) 2009 American Chemical Society

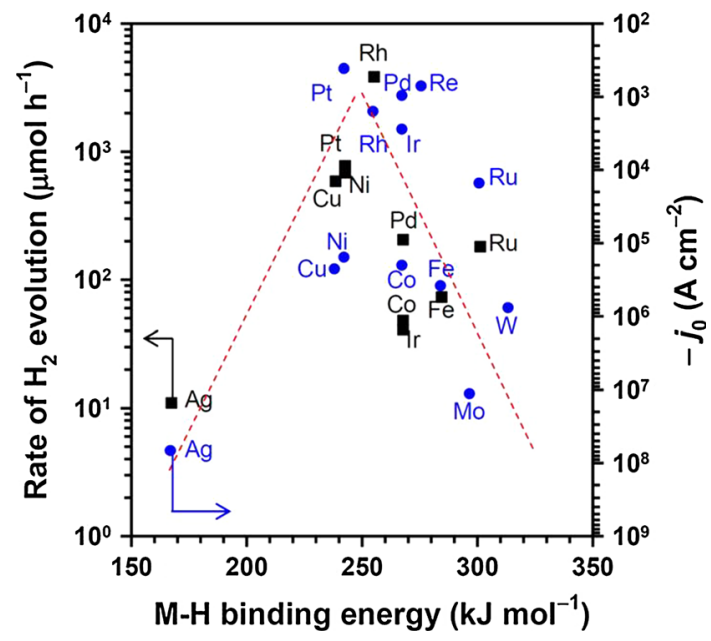

Fig. 6 Hydrogen evolution rate during overall water splitting using a $\left(\mathrm{Ga}_{1-x} \mathrm{Zn}_{x}\right)\left(\mathrm{N}_{1-x} \mathrm{O}_{x}\right)$ photocatalyst modified with various metal-chromium oxide cocatalysts (square) and exchange current for the electrolytic evolution of hydrogen on metals (circle) as a function of the $\mathrm{M}-\mathrm{H}$ binding energy. Reprinted from Ref. [40] with permission. Copyright (C) 2011 De Gruyter

It is natural to assume that the evolution of $\mathrm{H}_{2}$ and $\mathrm{O}_{2}$ in photocatalytic overall water splitting occurs via redox reaction paths analogous to electrochemical $\mathrm{H}_{2}$ and $\mathrm{O}_{2}$ evolution. In reality, the main determinant of the overall water-splitting rates was found to be the activity of $\mathrm{H}_{2}$ evolution cocatalysts using the $\left(\mathrm{Ga}_{1-x} \mathrm{Zn}_{x}\right)\left(\mathrm{N}_{1-x} \mathrm{O}_{x}\right)$ photocatalyst. Figure 6 shows the correlation of the 


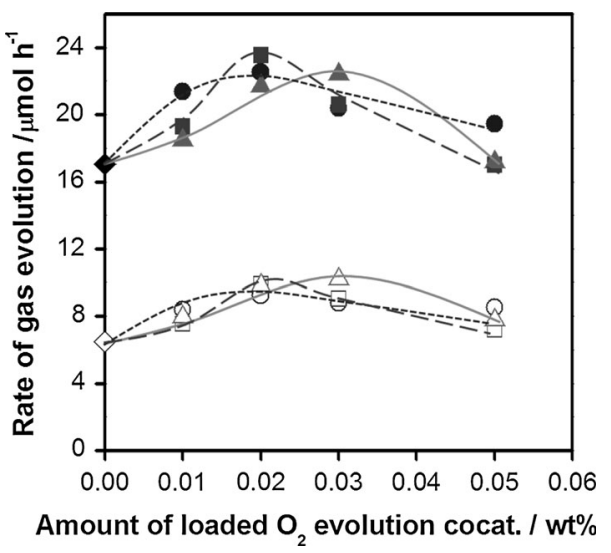

Fig. 7 Photocatalytic activity of $\left(\mathrm{Ga}_{1-x} \mathrm{Zn}_{x}\right)\left(\mathrm{N}_{1-x} \mathrm{O}_{x}\right)$ coloaded with different $\mathrm{O}_{2}$ evolution cocatalysts and $\mathrm{Rh} / \mathrm{Cr}_{2} \mathrm{O}_{3}$ for water splitting under visible light $(\lambda>420 \mathrm{~nm})$. Circles, triangles, and squares indicate the loading of $\mathrm{Mn}_{3} \mathrm{O}_{4}, \mathrm{IrO}_{2}$, and $\mathrm{RuO}_{2}$, respectively. Closed and open symbols denote $\mathrm{H}_{2}$ and $\mathrm{O}_{2}$, respectively. Reprinted from Ref. [31] with permission. (C) 2014 Wiley-VCH Verlag GmbH \& Co. KGaA, Weinheim

conventional volcano plot reported by Trasatti for $\mathrm{H}_{2}$ production in an acid solution with different metals [52] and the photocatalytic activity for overall water splitting (only $\mathrm{H}_{2}$ rates are shown in the figure) using a $\left(\mathrm{Ga}_{1-x}\right.$ $\left.\mathrm{Zn}_{x}\right)\left(\mathrm{N}_{1-x} \mathrm{O}_{x}\right)$ photocatalyst modified with metal-chromium oxide cocatalysts [47] as a function of the $\mathrm{M}-\mathrm{H}$ binding energy obtained from experimental data for a polycrystalline surface [52, 53]. This plot illustrates the good agreement between the electrochemical activity (exchange current density) for $\mathrm{H}_{2}$ production and the photocatalytic activity, suggesting that the reaction parameters and steps involved for these two cases are similar or identical. Additionally, the identity of the metal species has an extremely strong effect on the overall photocatalytic performance, suggesting that the chromium oxide component is not kinetically relevant. The metal particle size alone significantly affects the overall efficiency for both electrochemical and photocatalytic reactions [54]. Therefore, one should rigorously account for the metal particle size.

The loading of oxygen evolution cocatalysts has a weaker effect on the photocatalytic activity than the loading of hydrogen evolution cocatalysts. For example, the loading of $\mathrm{Mn}_{3} \mathrm{O}_{4}$ alone as an oxygen evolution cocatalyst on $\left(\mathrm{Ga}_{1-x} \mathrm{Zn}_{x}\right)\left(\mathrm{N}_{1-x} \mathrm{O}_{x}\right)$ does not allow for overall water splitting because of the lack of hydrogen evolution sites [9]. The loading of $\mathrm{Mn}_{3} \mathrm{O}_{4}, \mathrm{RuO}_{2}$, and $\mathrm{IrO}_{2}$ as oxygen evolution cocatalysts is effective when they are coloaded on the photocatalyst with a hydrogen evolution cocatalyst, such as an $\mathrm{Rh} / \mathrm{Cr}_{2} \mathrm{O}_{3}$ core/shell composite $[9,31]$. However, the optimal loading amounts of oxygen evolution cocatalysts were below $0.05 \mathrm{wt} \%$ (see Fig. 7), whereas the typical loading amount of $\mathrm{Rh}_{2-y} \mathrm{Cr}_{y} \mathrm{O}_{3}$ as a hydrogen evolution cocatalyst was $1 \mathrm{wt} \%$ (for $\mathrm{Rh}$ alone) or higher [31]. Moreover, coloading with oxygen evolution cocatalysts improved the water-splitting rates by a factor of 1.4 at most, regardless of the identity of the cocatalyst. These results suggest that the photocatalytic activity was limited by the hydrogen evolution process. However, coloading with oxygen evolution cocatalysts significantly improved the durability of the non-oxide photocatalysts, as the photooxidation of water and the photocatalyst itself compete on the surface. Coloading $\mathrm{RuO}_{2}$ on $\left(\mathrm{Ga}_{1-x} \mathrm{Zn}_{x}\right)\left(\mathrm{N}_{1-x} \mathrm{O}_{x}\right)$ along with $\mathrm{Rh} / \mathrm{Cr}_{2} \mathrm{O}_{3}$ was found to suppress the loss of nitrogen on the photocatalyst during photocatalytic water splitting [55]. As a result, the deactivation of the photocatalyst was also suppressed.

\subsection{TaON-Based Photocatalyst}

Recently, $\mathrm{ZrO}_{2}$-modified $\mathrm{TaON}\left(\mathrm{ZrO}_{2} / \mathrm{TaON}\right)$ was also reported to be active for overall water splitting when coloaded with cocatalysts for both hydrogen and oxygen evolution. This was the first report of overall water splitting by a transition metal oxynitride [56]. TaON is known to generate hydrogen and oxygen under visible light illumination in the presence of methanol and silver cations, respectively. TaON exhibited an acceptable AQY for the sacrificial OER but not the sacrificial HER, even with cocatalyst modifications. In addition, TaON generated only a small amount of hydrogen and no oxygen when it was applied to overall water splitting. These results suggest that the photoexcited electrons did not migrate to cocatalysts effectively because of a high defect density in $\mathrm{TaON}$ and/or because photoexcited holes were consumed by the selfoxidation of $\mathrm{TaON}$ rather than water oxidation. Therefore, it was necessary to improve the $\mathrm{TaON}$ synthesis conditions and the cocatalyst loading methods.

Modifying $\mathrm{Ta}_{2} \mathrm{O}_{5}$ with $\mathrm{ZrO}_{2}$ prior to nitridation effectively suppressed the reduction of pentavalent $\mathrm{Ta}$ ions during nitridation [57]. Figure 8 shows the absorption spectra of $\mathrm{TaON}$ and $\mathrm{ZrO}_{2}$-modified TaON [57]. Unmodified $\mathrm{TaON}$ exhibits light absorption due to reduced $\mathrm{Ta}$ species at a wavelength longer than $500 \mathrm{~nm}$, the absorption edge wavelength of TaON. Such background light absorption is significantly suppressed for $\mathrm{ZrO}_{2}$-modified TaON, likely because ionic $\mathrm{Zr}^{4+}$ is not significantly reduced to generate anion vacancies during nitridation. Photoluminescence spectroscopy and photoelectrochemical measurements revealed that the n-type semiconducting character of $\mathrm{TaON}$ was moderated by the $\mathrm{ZrO}_{2}$ modification. The photocatalytic activity of $\mathrm{TaON}$ for sacrificial hydrogen evolution improved as a result of modification with $\mathrm{ZrO}_{2}$. 


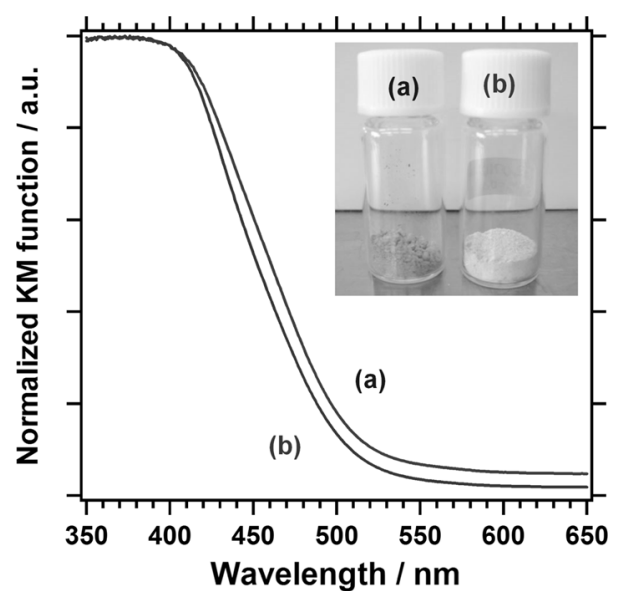

Fig. 8 Diffuse reflectance spectra of (a) $\mathrm{TaON}$ and (b) $\mathrm{ZrO}_{2} / \mathrm{TaON}$. Adapted from Ref. [57] with permission. Copyright (c) 2008 The Chemical Society of Japan

Subsequently, the coloading of a core/shell-type hydrogen evolution cocatalyst and an oxygen evolution cocatalyst was found to enable overall water splitting using $\mathrm{ZrO}_{2} / \mathrm{TaON}$ [56]. $\mathrm{ZrO}_{2} / \mathrm{TaON}$ was modified with a $\mathrm{RuO}_{x} /$ $\mathrm{Cr}_{2} \mathrm{O}_{3}$ core/shell-type hydrogen evolution cocatalyst and then with $\mathrm{IrO}_{2}$ as an oxygen evolution cocatalyst. $\mathrm{ZrO}_{2} /$ TaON modified with $\mathrm{RuO}_{x} / \mathrm{Cr}_{2} \mathrm{O}_{3}$ exhibited some activity for overall water splitting under UV illumination, although the gas evolution rates decreased over time because of the deactivation of the photocatalyst. When $\mathrm{IrO}_{2}$ was coloaded as an oxygen evolution cocatalyst on $\mathrm{ZrO}_{2} / \mathrm{TaON}$ with $\mathrm{RuO}_{x} / \mathrm{Cr}_{2} \mathrm{O}_{3}$, overall water splitting proceeded steadily. By optimizing the preparation conditions for the photocatalyst/ cocatalyst composite, overall water splitting was achieved, even under visible light irradiation. Coloading with $\mathrm{RuO}_{x}$ and $\mathrm{IrO}_{2}$ did not lead to oxygen evolution. These results highlight the importance of activation and stabilization of the photocatalyst by the coloading of hydrogen and oxygen evolution cocatalysts and the suppression of side reactions by the ultrathin chromia layer.

\subsection{Doped $\mathrm{SrTiO}_{3}$ Photocatalysts}

Overall water splitting was also achieved under visible light using rhodium- and antimony-codoped $\mathrm{SrTiO}_{3}$ $\left(\mathrm{SrTiO}_{3}: \mathrm{Rh}, \mathrm{Sb}\right)$ loaded with $\mathrm{IrO}_{2}, \mathrm{RuO}_{2}$, or $\mathrm{Ru}$ as cocatalysts [58]. Among the three cocatalysts, $\mathrm{IrO}_{2}$ produced the highest activity for overall water splitting. In this photocatalyst, donor levels consisting of trivalent Rh species are excited under visible light. Electrons and holes are generated in the conduction band composed by Ti $3 \mathrm{~d}$ orbitals and the impurity levels consisting of Rh species. Codoping with $\mathrm{Sb}^{5+}$ ions stabilizes the donor level formed by $\mathrm{Rh}^{3+}$ and
Table 2 Correlation of photocatalyst diameter with the number of photons that strike a cross-section of a spherical photocatalyst particle per unit time and the time interval between photons hitting the particle [40]

\begin{tabular}{llll}
\hline $\begin{array}{l}\text { Diameter of } \\
\text { the spherical } \\
\text { photocatalyst/ } \\
\text { nm }\end{array}$ & $\begin{array}{l}\text { Cross-section } \\
\text { of the } \\
\text { spherical } \\
\text { photocatalyst/ } \\
\text { cm }^{-2}\end{array}$ & $\begin{array}{l}\text { Number of } \\
\text { photons that } \\
\text { strike a single } \\
\text { photocatalyst } \\
\text { particle/s }\end{array}$ & $\begin{array}{l}\text { Time interval } \\
\text { between photons } \\
\text { striking a single } \\
\text { photocatalyst } \\
\text { particle/ } \mu \mathrm{s}\end{array}$ \\
\hline 50 & $2.0 \times 10^{-11}$ & $1.8 \times 10^{6}$ & $5.6 \times 10^{-1}$ \\
100 & $7.9 \times 10^{-11}$ & $7.1 \times 10^{6}$ & $1.4 \times 10^{-1}$ \\
500 & $2.0 \times 10^{-9}$ & $1.8 \times 10^{8}$ & $5.6 \times 10^{-3}$ \\
1,000 & $7.9 \times 10^{-9}$ & $7.1 \times 10^{8}$ & $1.4 \times 10^{-3}$ \\
5,000 & $2.0 \times 10^{-7}$ & $1.8 \times 10^{10}$ & $5.6 \times 10^{-5}$ \\
\hline
\end{tabular}

The number of the photons is calculated by integrating from 280 to $600 \mathrm{~nm}$ of AM 1.5G

enables oxygen evolution on $\mathrm{Rh}$-doped $\mathrm{SrTiO}_{3}$ in the presence of sacrificial reagents. The reactivity of photoexcited holes in impurity levels for the oxidation of water is not typically high because of the low mobility and short lifetimes of the holes. Loading of $\mathrm{IrO}_{2}$ improved the oxygen evolution activity of $\mathrm{SrTiO}_{3}: \mathrm{Rh}, \mathrm{Sb}$, as confirmed by the sacrificial OER. Interestingly, the loading of $\mathrm{IrO}_{2}$ also improved the photocatalytic activity of the sacrificial HER. Thus, $\mathrm{IrO}_{2}$, a well-known cocatalyst for $\mathrm{O}_{2}$ evolution, enhanced both the hydrogen and oxygen evolution in water splitting using $\mathrm{SrTiO}_{3}: \mathrm{Rh}$,Sb. It was suggested that that partially reduced $\mathrm{IrO}_{2}$ worked as an active site for $\mathrm{H}_{2}$ evolution.

\section{Kinetic Aspects}

\subsection{Light Intensity and Cocatalyst Loading Amounts}

Photocatalytic reactions are initiated by the absorption of photons by photocatalysts. This absorption generates electron-hole pairs that dissociate into photoexcited electrons and holes (electron vacancies). The photocatalyst particle size plays an important role in determining how many photons are absorbed by a particle. Table 2 shows the number of photons that strike the cross-section of a single spherical particle per unit time and its inverse, which represents the expected time difference between photons striking a single particle, as a function of particle diameter [40]. The number of incident photons per unit area is estimated based on the solar flux of standard AM 1.5G from UV to $600-\mathrm{nm}$ visible light. Increasing the photocatalyst particle size will clearly increase the number of photons that strike a photocatalyst particle. However, a particle with a typical diameter of $100 \mathrm{~nm}$ will receive $10^{7}$ photons $\mathrm{s}^{-1}$, which corresponds to a time of only $0.1 \mu \mathrm{s}$ 
between photons striking a photocatalyst particle. This timespan is comparable to those of chemical reactions (typically on the order of microseconds or longer). One should adequately account for this dependence of the number of photons collected per particle on the particle size. It is important to carefully measure and consider the light intensity (that of either solar radiation or laser pulses) when discussing the photocatalytic activity because the number of photons per unit time and the resulting photocatalytic pathways may differ greatly for different light intensities.

The rate of a photocatalytic reaction increases with increasing excitation intensity, although not necessarily in a proportional manner. Some reaction models suggest that the reaction order for light intensity decreases from unity to one half as the light intensity increases [59]. This decrease occurs because the recombination of photoexcited carriers is second-order with respect to carrier concentrations (proportional to both electron and hole concentrations). In contrast, under low light intensities, at which the concentration of photoexcited carriers is negligible with respect to the intrinsic majority carrier concentration, it is reasonable to assume that only the minority carrier concentration depends on the excitation intensity, whereas the majority carrier concentration is constant. As a result, the recombination reaction is approximated as a quasi-first-order reaction with respect to the minority carrier concentration generated by photoexcitation, and the photocatalytic reaction rate becomes proportional to the light intensity. Accordingly, the reaction order for light intensity can be an indirect measure of how many photoexcited carriers exist in photocatalyst particles under illumination.

Figure 9 shows the light intensity dependence of the water-splitting rates obtained using $\left(\mathrm{Ga}_{1-x} \mathrm{Zn}_{x}\right)\left(\mathrm{N}_{1-x} \mathrm{O}_{x}\right)$ modified with various amounts of $\mathrm{Rh}_{2-y} \mathrm{Cr}_{y} \mathrm{O}_{3}$ as a hydrogen evolution cocatalyst [59]. The $\left(\mathrm{Ga}_{1-x} \mathrm{Zn}_{x}\right)\left(\mathrm{N}_{1-x}\right.$ $\mathrm{O}_{x}$ ) was prepared by nitriding a mixture of $\mathrm{ZnO}$ and $\mathrm{Ga}_{2} \mathrm{O}_{3}$ under $\mathrm{NH}_{3}$ flow, and $\mathrm{Rh}_{2-y} \mathrm{Cr}_{y} \mathrm{O}_{3}$ was loaded by an impregnation method using $\mathrm{Na}_{3} \mathrm{RhCl}_{6}$ and $\mathrm{Cr}\left(\mathrm{NO}_{3}\right)_{3}$ as precursors. The AQY of the photocatalytic overall water splitting using the obtained $\mathrm{Rh}_{2-y} \mathrm{Cr}_{y} \mathrm{O}_{3} /\left(\mathrm{Ga}_{1-x} \mathrm{Zn}_{x}\right)\left(\mathrm{N}_{1-x}\right.$ $\mathrm{O}_{x}$ ) was $0.5 \%$ at $420 \mathrm{~nm}$. The reaction rate was proportional to light intensity when the $\left(\mathrm{Ga}_{1-x} \mathrm{Zn}_{x}\right)\left(\mathrm{N}_{1-x} \mathrm{O}_{x}\right)$ was modified with a sufficient amount of $\mathrm{Rh}_{2-y} \mathrm{Cr}_{y} \mathrm{O}_{3}$. However, the reaction order for light intensity decreased as the cocatalyst loading decreased, and the water-splitting rate decreased. The steady-state concentration of photoexcited carriers under photoexcitation is determined by the balance of the rates of carrier generation by photoexcitation and carrier consumption by surface reactions and recombination. The above result suggests that charge recombination was enhanced by reducing the cocatalyst loading because

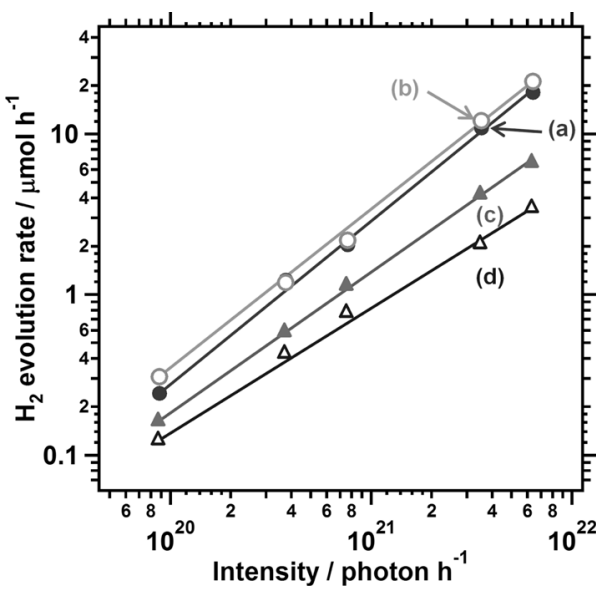

Fig. 9 Effect of the light intensity and loading amount of $\mathrm{Rh}_{2-y}$ $\mathrm{Cr}_{y} \mathrm{O}_{3}$ cocatalyst on the photocatalytic activity of $\mathrm{Rh}_{2-y} \mathrm{Cr}_{y} \mathrm{O}_{3} /\left(\mathrm{Ga}_{1-x}\right.$ $\left.\mathrm{Zn}_{x}\right)\left(\mathrm{N}_{1-x} \mathrm{O}_{x}\right)$ for water splitting. The amount of $\mathrm{Rh}_{2-y} \mathrm{Cr}_{y} \mathrm{O}_{3}$ loaded was (a) Rh $3.0 \mathrm{wt} \%, \mathrm{Cr} 4.5 \mathrm{wt} \%$. (b) Rh $1.0 \mathrm{wt} \%$, Cr $1.5 \mathrm{wt} \%$. (c) Rh $0.2 \mathrm{wt} \%, \mathrm{Cr} 0.3 \mathrm{wt} \%$. (d) $\mathrm{Rh} 0.1 \mathrm{wt} \%, \mathrm{Cr} 0.15 \mathrm{wt} \%$. The reactions were performed under Xe lamp illumination $(300 \mathrm{~nm}<\lambda$ $<500 \mathrm{~nm}$ ). Reprinted with permission from Ref. [59]. Copyright (C) 2009 American Chemical Society

the hydrogen evolution process created a bottleneck. In contrast, when excessive cocatalyst was loaded, the reaction rate slowed but remained proportional to the light intensity. In this situation, a low concentration of photoexcited electrons would be expected as a result of the facilitation of the hydrogen evolution processes, giving rise to the observed proportionality of the water-splitting rate to the light intensity. However, excessive cocatalyst loading could instead cause the aggregation of cocatalyst particles, photocatalyst shading, and/or blockage of oxygen evolution sites on the photocatalyst surfaces. As a result, the water-splitting rate decreased with increasing loading of the hydrogen evolution cocatalyst. Therefore, it is important to optimize the cocatalyst loading amounts for the light intensity used in the application of interest to maximize the performance of the photocatalytic system.

The activities of most photocatalysts follow the aforementioned light intensity dependency; that is, the reaction order changes from unity to one half as the light intensity increases. This statement means that the AQY decreases monotonically with increasing light intensity. However, in some cases, the AQY of photocatalytic water splitting increases with increasing light intensity under weak excitation conditions. To achieve a high quantum efficiency, it is likely necessary to saturate certain trap states with photoexcited carriers by generating photoexcited carriers at a higher rate than the charge recombination mediated by the trap states to endow the photoexcited carriers with high mobility. 


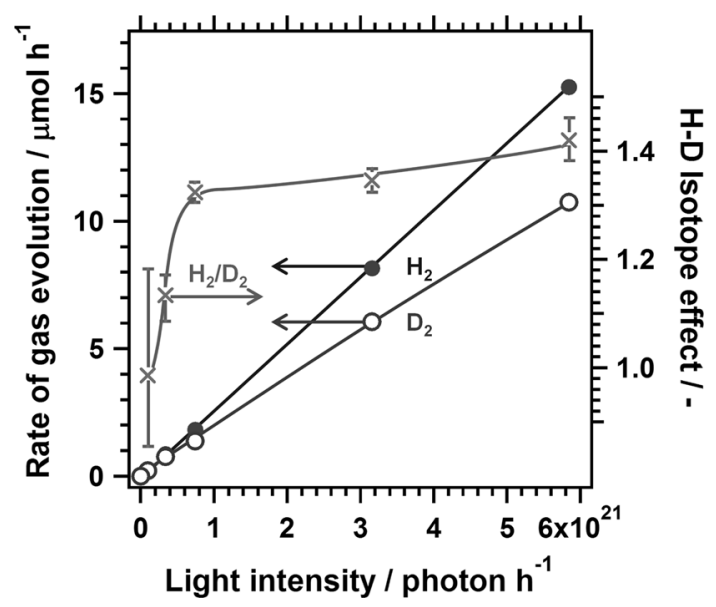

Fig. 10 Influence of light intensity on the $\mathrm{H}-\mathrm{D}$ isotope effect in the water-splitting reaction using $\mathrm{Rh}_{2-y} \mathrm{Cr}_{y} \mathrm{O}_{3} /\left(\mathrm{Ga}_{1-x} \mathrm{Zn}_{x}\right)\left(\mathrm{N}_{1-x} \mathrm{O}_{x}\right)$. The reactions were performed under $\mathrm{Xe}$ lamp illumination (300 $\mathrm{nm}<\lambda<500 \mathrm{~nm}$ ). Reprinted with permission from Ref. [59]. Copyright (c) 2009 American Chemical Society

\subsection{Hydrogen-Deuterium Isotope Effect}

The hydrogen-deuterium (H-D) isotope effect results from reaction processes involving hydrogen (deuterium) atoms at the interface of a photocatalyst and a reaction solution and is expected to reflect the reaction mechanism of the rate-determining step. However, when processes occurring inside a photocatalyst particle have a significant influence on the overall reaction rate, the H-D isotope effect should be small because hydrogen atoms are not involved in the rate-determining step.

The H-D isotope effect was investigated using $\left(\mathrm{Ga}_{1-x}\right.$ $\left.\mathrm{Zn}_{x}\right)\left(\mathrm{N}_{1-x} \mathrm{O}_{x}\right)$ and $\mathrm{Zn}$-added $\mathrm{Ga}_{2} \mathrm{O}_{3}\left(\mathrm{Ga}_{2} \mathrm{O}_{3}: \mathrm{Zn}\right)$ modified with $\mathrm{Rh}_{2-y} \mathrm{Cr}_{y} \mathrm{O}_{3}$. Figure 10 shows the rates of light water $\left(\mathrm{H}_{2} \mathrm{O}\right)$ and heavy water $\left(\mathrm{D}_{2} \mathrm{O}\right)$ splitting and the $\mathrm{H}-\mathrm{D}$ isotope effect using $\mathrm{Rh}_{2-y} \mathrm{Cr}_{y} \mathrm{O}_{3} /\left(\mathrm{Ga}_{1-x} \mathrm{Zn}_{x}\right)\left(\mathrm{N}_{1-x} \mathrm{O}_{x}\right)$ under various light intensities, with the $\mathrm{H}-\mathrm{D}$ isotope effect defined as the ratio of the $\mathrm{H}_{2} \mathrm{O}$ - and $\mathrm{D}_{2} \mathrm{O}$-splitting rates [59]. The maximum H-D isotope effect for the photocatalytic water-splitting reaction was 1.4 , which was smaller than that for typical chemical reactions. In addition, the H-D isotope effect did not change significantly when various sacrificial electron donors or acceptors were added, as shown in Table 3 [59]. The H-D isotope effect would change drastically upon the addition of sacrificial reagents that react more readily than water if it originated from surface reactions. Therefore, these results suggest that it was largely independent of surface reactions. The rates of $\mathrm{H}_{2} \mathrm{O}$ and $\mathrm{D}_{2} \mathrm{O}$ splitting were the same when the light intensity was extremely weak. This result suggests that the water-splitting rate on $\mathrm{Rh}_{2-y} \mathrm{Cr}_{y} \mathrm{O}_{3} /\left(\mathrm{Ga}_{1-x} \mathrm{Zn}_{x}\right)\left(\mathrm{N}_{1-x} \mathrm{O}_{x}\right)$ was primarily controlled by processes within the
Table $3 \mathrm{H}-\mathrm{D}$ isotope effect and apparent activation energy for photocatalytic water splitting using $\mathrm{Rh}_{2-y} \mathrm{Cr}_{y} \mathrm{O}_{3} /\left(\mathrm{Ga}_{1-x} \mathrm{Zn}_{x}\right)\left(\mathrm{N}_{1-x} \mathrm{O}_{x}\right)$ in the presence of sacrificial reagents [59]

\begin{tabular}{llll}
\hline Sacrificial reagent & Reaction & Isotope effect ${ }^{\mathrm{a}} /-$ & $E_{\mathrm{a}}^{\mathrm{b}} / \mathrm{kJ} \mathrm{mol}^{-1}$ \\
\hline $\mathrm{None}^{\mathrm{c}}$ & Water splitting & 1.4 & 8 \\
$\mathrm{CH}_{3} \mathrm{OH}^{\mathrm{d}}$ & $\mathrm{H}_{2}$ evolution & 1.5 & 10 \\
$\mathrm{CH}_{3} \mathrm{CH}_{2} \mathrm{OH}^{\mathrm{e}}$ & $\mathrm{H}_{2}$ evolution & - & 9 \\
$\mathrm{C}_{2} \mathrm{O}_{4}{ }^{2-}, \mathrm{HC}_{2} \mathrm{O}_{4}^{-\mathrm{f}}$ & $\mathrm{H}_{2}$ evolution & 1.2 & - \\
$\mathrm{HCO}_{2}^{-\mathrm{g}}$ & $\mathrm{H}_{2}$ evolution & 1.8 & - \\
$\mathrm{Ag}^{+\mathrm{h}}$ & $\mathrm{O}_{2}$ evolution & 1.3 & 9
\end{tabular}

Reaction conditions: $\mathrm{Rh}_{2-y} \mathrm{Cr}_{y} \mathrm{O}_{3} /\left(\mathrm{Ga}_{1-x} \mathrm{Zn}_{x}\right)\left(\mathrm{N}_{1-x} \mathrm{O}_{x}\right), 0.10 \mathrm{~g} ; \mathrm{H}_{2} \mathrm{O}$ $\left(\mathrm{D}_{2} \mathrm{O}\right)$ containing the sacrificial reagents, $140 \mathrm{~mL}$; light source, $300 \mathrm{~W}$ Xe lamp $(300 \mathrm{~nm}<\lambda<500 \mathrm{~nm})$

a Ratio of the gas evolution rates from $\mathrm{H}_{2} \mathrm{O}$ solutions to those from $\mathrm{D}_{2} \mathrm{O}$ solutions

b Apparent activation energy

c $\mathrm{The} \mathrm{pH}$ of the solutions was adjusted to 4.5 by $\mathrm{H}_{2} \mathrm{SO}_{4}$

d 10 and 80 vol $\% \mathrm{CH}_{3} \mathrm{OH}$ aqueous solutions for the measurement of the isotope effect and apparent activation energy, respectively

e 80 vol \% $\mathrm{CH}_{3} \mathrm{CH}_{2} \mathrm{OH}$ aqueous solutions

f $45 \mathrm{mM}(\mathrm{COONa})_{2}$ and $5 \mathrm{mM}(\mathrm{COOH})_{2}$ aqueous solutions

g $50 \mathrm{mM}$ HCOONa aqueous solutions

h $50 \mathrm{mM} \mathrm{AgNO}_{3}$ aqueous solutions

Table 4 Effect of reaction conditions on the H-D isotope effect and apparent activation energy for photocatalytic water splitting using $\mathrm{Rh}_{2-y} \mathrm{Cr}_{y} \mathrm{O}_{3} / \mathrm{Ga}_{2} \mathrm{O}_{3}: \mathrm{Zn}[60]$

\begin{tabular}{|c|c|c|c|c|}
\hline $\mathrm{Ga}_{2} \mathrm{O}_{3}: \mathrm{Zn} / \mathrm{g}$ & $\begin{array}{l}\mathrm{Rh}_{2-y} \\
\mathrm{Cr}_{y} \mathrm{O}_{3} / \mathrm{wt} \%\end{array}$ & $\begin{array}{l}\text { Light } \\
\text { source }^{a}\end{array}$ & $\begin{array}{l}\text { Water- } \\
\text { splitting rate/ } \\
\mathrm{mmol} \mathrm{h}^{-1}\end{array}$ & $\begin{array}{l}\text { Isotope } \\
\text { effect } \%\end{array}$ \\
\hline 0.4 & Rh $0.5-\mathrm{Cr} 0.75$ & $\mathrm{Xe}$ & 0.11 & 1.0 \\
\hline 0.4 & $\mathrm{Rh} 0.5-\mathrm{Cr} 0.75$ & $\mathrm{Hg}$ & 11.2 & 1.2 \\
\hline 0.4 & $\mathrm{Rh} 0.05-\mathrm{Cr} 0.075$ & $\mathrm{Hg}$ & 7.3 & 1.4 \\
\hline 0.04 & Rh $0.05-\mathrm{Cr} 0.075$ & $\mathrm{Hg}$ & 1.0 & 1.9 \\
\hline
\end{tabular}

a $X e 300 \mathrm{~W}$ Xe lamp $(200 \mathrm{~nm}<\lambda<500 \mathrm{~nm}), \mathrm{Hg} 450 \mathrm{~W}$ Xe lamp $(\lambda>200 \mathrm{~nm})$

b Ratio of $\mathrm{H}_{2} \mathrm{O}$ - and $\mathrm{D}_{2} \mathrm{O}$-splitting rates. Reprinted with permission from Ref. [60]. Copyright (C) 2010, Elsevier

photocatalyst, such as photoexcitation and/or the migration of photoexcited carriers to the surface, rather than surface redox reactions involving hydrogen atoms.

$\mathrm{Rh}_{2-y} \mathrm{Cr}_{y} \mathrm{O}_{3} / \mathrm{Ga}_{2} \mathrm{O}_{3}: \mathrm{Zn}$, which can split water with an AQY of over $10 \%$, was used to further study the isotope effect in photocatalytic water splitting because the photocatalytic activity of $\mathrm{Rh}_{2-y} \mathrm{Cr}_{y} \mathrm{O}_{3} /\left(\mathrm{Ga}_{1-x} \mathrm{Zn}_{x}\right)\left(\mathrm{N}_{1-x} \mathrm{O}_{x}\right)$ could be effectively controlled by charge recombination due to the relatively low AQY. The effects of the reaction conditions on the water-splitting rate and isotope effect for $\mathrm{Rh}_{2-y} \mathrm{Cr}_{y} \mathrm{O}_{3} / \mathrm{Ga}_{2} \mathrm{O}_{3}: \mathrm{Zn}$ are presented in Table 4 [60]. The $\mathrm{H}-\mathrm{D}$ isotope effect became stronger as the excitation frequency per photocatalyst particle was increased by increasing the light intensity and decreasing the amount of 
photocatalyst. The H-D isotope effect also became stronger when the amount of loaded cocatalyst was decreased to suppress HER. However, the H-D isotope effect was at most two, even when the photocatalytic water splitting was carried out using $\mathrm{Rh}_{2-y} \mathrm{Cr}_{y} \mathrm{O}_{3} / \mathrm{Ga}_{2} \mathrm{O}_{3}: \mathrm{Zn}$ at decent rates. These results suggest that in most cases, the photocatalytic water-splitting rate is mainly determined by bulk processes inside the photocatalyst particles.

\subsection{Activation Energy}

The effect of reaction temperature on the photocatalytic activity for water splitting was investigated using $\left(\mathrm{Ga}_{1-x}\right.$ $\left.\mathrm{Zn}_{x}\right)\left(\mathrm{N}_{1-x} \mathrm{O}_{x}\right)$ and $\mathrm{Ga}_{2} \mathrm{O}_{3}: \mathrm{Zn}$ modified with various cocatalysts. It is natural to expect that the apparent activation energy of photocatalytic water splitting reflects the activation energy of the slowest reaction step and that reaction processes involving the cleavage and formation of chemical bonds have higher activation energies than physical processes, such as charge migration.

The apparent activation energy for photocatalytic water splitting using $\mathrm{Rh}_{2-y} \mathrm{Cr}_{y} \mathrm{O}_{3} /\left(\mathrm{Ga}_{1-x} \mathrm{Zn}_{x}\right)\left(\mathrm{N}_{1-x} \mathrm{O}_{x}\right)$ and $\mathrm{Rh}_{2-y}$ $\mathrm{Cr}_{y} \mathrm{O}_{3} / \mathrm{Ga}_{2} \mathrm{O}_{3}: \mathrm{Zn}$ was $8 \mathrm{~kJ} \mathrm{~mol}^{-1}$ from 298 to $323 \mathrm{~K} \mathrm{[59,}$ 60]. This apparent activation energy is significantly lower than that for the electrochemical HER on Rh electrodes $\left(31 \mathrm{~kJ} \mathrm{~mol}^{-1}\right)$ [61]. Moreover, the apparent activation energies for $\mathrm{D}_{2} \mathrm{O}$ splitting, water splitting in the presence of sacrificial reagents, and gas-phase water vapor splitting were highly similar when $\mathrm{Rh}_{2-y} \mathrm{Cr}_{y} \mathrm{O}_{3} /\left(\mathrm{Ga}_{1-x} \mathrm{Zn}_{x}\right)\left(\mathrm{N}_{1-x} \mathrm{O}_{x}\right)$ was used [59, 62]. This observation indicates that the apparent activation energy is associated with processes occurring inside the photocatalyst rather than the formation and dissociation of chemical bonds involving hydrogen or the diffusion, adsorption, and desorption of chemical species. This association likely occurs because only electrons that have successfully escaped recombination with photoexcited holes can contribute to the photocatalytic HER on the surface, whereas the electrons needed to drive hydrogen evolution can be supplied immediately, depending on the potential of the electrode in the electrochemical HER.

The apparent activation energy depends on the type of cocatalyst. For example, loading $\mathrm{Ni}$ instead of $\mathrm{Rh}_{2-y} \mathrm{Cr}_{y} \mathrm{O}_{3}$ on $\mathrm{Ga}_{2} \mathrm{O}_{3}: \mathrm{Zn}$ increased the apparent activation energy from 8 to $15 \mathrm{~kJ} \mathrm{~mol}^{-1}$ while lowering the water-splitting rate at room temperature to $40 \%$ [60]. This result suggests that reaction processes involving both the photocatalyst and cocatalysts, such as electron transfer from the photocatalyst to the cocatalyst, contributed to the apparent activation energy. In fact, surface-enhanced infrared spectroscopy under potential control revealed that there was a potential barrier for electron migration at the interface between an n-type GaN single crystal and deposited Pt particles [63]. The slightly higher activation energy of Ni could also be associated with surface electrochemical reactions, considering the relatively low electrochemical activity of Ni. The apparent activation energy for HER on $\mathrm{Ni}$ was reported to be $56 \mathrm{~kJ} \mathrm{~mol}^{-1}$ [64]. However, the apparent activation energy is often considerably lower for photocatalytic reactions than for electrochemical HER using corresponding electrodes because bulk processes have a dominant effect on the apparent activation energy.

When $\left(\mathrm{Ga}_{1-x} \mathrm{Zn}_{x}\right)\left(\mathrm{N}_{1-x} \mathrm{O}_{x}\right)$ was modified with $\mathrm{RuO}_{2}$ instead of $\mathrm{Rh}_{2-y} \mathrm{Cr}_{y} \mathrm{O}_{3}$, the apparent activation energy decreased from 8 to $0 \mathrm{~kJ} \mathrm{~mol}^{-1}$ and the water-splitting rate decreased to $40 \%$ [2]. This change in the water-splitting rate cannot be explained by the apparent activation energy alone. Side reactions, such as oxygen reduction, compete with hydrogen evolution on $\mathrm{RuO}_{2}$, whereas $\mathrm{Rh}_{2-y} \mathrm{Cr}_{y} \mathrm{O}_{3}$ is selectively active for hydrogen evolution [49]. As a result, the water-splitting rate on $\mathrm{RuO}_{2} /\left(\mathrm{Ga}_{1-x} \mathrm{Zn}_{x}\right)\left(\mathrm{N}_{1-x} \mathrm{O}_{x}\right)$ decreases drastically in the presence of oxygen. Such competing reactions could significantly complicate the kinetics of photocatalysis.

\section{Concluding Remarks}

Some examples of powder photocatalysts for successful overall water splitting and their reaction kinetics are overviewed. The photocatalytic reactions using a particulate semiconductor are distinct from thermocatalytic reactions, as the former involves photophysical processes inside semiconductors, which regulates how many charge carriers are available in surface electrochemical redox reactions. Consequently, the kinetic parameters of photocatalytic water splitting, such as the H-D isotope effect and apparent activation energy, can be significantly lower than those for electrochemical water splitting and thermocatalytic reactions. Considering that AQYs lower than $10 \%$ have been reported for water-splitting reactions in visible light regions, a major challenge lies in the efficiency and selectivity of the separation of photoexcited charge carriers generated in visible-light-driven photocatalysts and their transfer to cocatalysts that work as active sites for surface redox reactions. Semiconductor photocatalysts for overall water splitting should be highly crystalline to prevent photoexcited charge carriers from becoming trapped and recombining at defective sites. At the same time, the dimension of photocatalyst particles must be chosen based on the diffusion length of minority carriers so that they can reach the surface active sites before recombination. Thus, it is necessary to balance the crystallinity and dimension of photocatalytic materials with the visible light response. The weight or surface area of a photocatalytic material is not a primary concern unless the photocatalytic reactions involve the cleavage of metal cations and organic 
pollutants at low concentrations. In such a case, where the rate is proportional to the reactant concentration, the photocatalytic reaction may be regulated by the adsorption of the reactants, and thus, high photonic efficiency cannot be expected.

Cocatalysts loaded on a photocatalyst play key roles in not only charge separation but also electrocatalytic functions. A correlation may be found between the electrocatalytic performances of cocatalyst components and the water-splitting activity of photocatalysts modified with the cocatalysts when sufficient photoexcited carriers are supplied for the surface redox reactions (i.e., the reaction is not limited by the physical process). The loading amount, dispersivity, and size of cocatalyst particles have considerable influence on the photocatalytic activity, suggesting that in addition to the electrocatalytic activity of surface redox reactions, electronic interaction at the cocatalystsemiconductor interface is crucial. It is expected that the flow of charge carriers can be rectified by the use of Schottky-type junctions. Alternatively, the potential barrier for charge migration from a photocatalyst to a cocatalyst may be minimized by creating ohmic contact at the interface. Additional loading of catalytic components may lead to the development of efficient cocatalysts in which charge separation and charge injection are functionally separated. Coloading of well-designed hydrogen evolution cocatalysts and oxygen evolution catalysts could enhance the charge separation and durability of photocatalytic materials under operation conditions. It is also important to control the selectivity of redox reactions caused by photoexcited charge carriers. The coating of hydrogen evolution catalysts with an ultrathin hydrated chromia layer has been found to effectively improve the reaction selectivity of photoexcited electrons toward the hydrogen evolution reaction because this layer can be penetrated by protons and hydrogen molecules but not by oxygen molecules and certain other electron acceptors. The reaction selectivity could be a substantial problem when the reaction is carried out using water with impurities.

Photocatalytic water splitting under sunlight could contribute to a sustainable society. However, drastic improvements in solar energy conversion efficiencies are still needed. It has been suggested that the solar energy conversion efficiency by photocatalytic water splitting should be $5 \%$ or higher. Photocatalysts should be active for water splitting under irradiation up to $600 \mathrm{~nm}$ or even longer wavelengths to achieve a sufficient solar energy conversion efficiency at a reasonable quantum efficiency. This goal requires the development of high-quality semiconductors that are active even under red and deep-red irradiation. To meet this challenge, it is important to understand the kinetic aspects of photocatalytic water splitting and the functionality of cocatalysts.
Acknowledgments This work was financially supported by Grantin-Aids for Specially Promoted Research (No. 23000009) and for Young Scientists (B) (No. 25810112) of the Japan Society for the Promotion of Science (JSPS) and King Abdullah University of Science and Technology. Further financial support came from the International Exchange Program of the A3 Foresight Program of JSPS and Companhia Brasileira de Metalurgia e Mineração (CBMM).

\section{References}

1. HBP Statistical Review of World Energy BP Statistical Review of World Energy, BP p.l.c, 1 St James's Square, London, June 2013

2. Hisatomi T, Minegishi T, Domen K (2012) Bull Chem Soc Jpn 85:647

3. Chen Z, Jaramillo TF, Deutsch TG, Kleiman-Shwarsctein A, Forman AJ, Gaillard N, Garland R, Takanabe K, Heske C, Sunkara M, McFarland EW, Domen K, Miller EL, Turner JA, Dinh HN (2010) J Mater Res 25:3

4. Hisatomi T, Kubota J, Domen K (2014) Chem Soc Rev. doi: 10. 1039/c3cs60378d

5. Pinaud BA, Benck JD, Seitz LC, Forman AJ, Chen Z, Deutsch TG, James BD, Baum KN, Baum GN, Ardo S, Wang H, Miller E, Jaramillo TF (2013) Energy Environ Sci 6:1983

6. Maeda K, Domen K (2010) J Phys Chem Lett 1:2655

7. Yamakata A, Ishibashi T, Kato H, Kudo A, Onishi H (2003) J Phys Chem B 107:14383

8. Maeda K, Teramura K, Lu D, Takata T, Saito N, Inoue Y, Domen K (2006) Nature 440:295

9. Maeda K, Xiong A, Yoshinaga T, Ikeda T, Sakamoto N, Hisatomi T, Takashima M, Lu D, Kanehara M, Setoyama T, Teranishi T, Domen K (2010) Angew Chem Int Ed 49:4096

10. Tamaki Y, Furube A, Murai M, Hara K, Katoh R, Tachiya M (2007) Phys Chem Chem Phys 9:1453

11. Yamakata A, Ishibashi T, Onishi H (2001) J Phys Chem B 105:7258

12. Tamaki Y, Furube A, Murai M, Hara K, Katoh R, Tachiya M (2006) J Am Chem Soc 128:416

13. Serpone N, Lawless D, Khairutdinov R, Pelizzetti E (1995) J Phys Chem 99:16655

14. Nosaka Y, Fox MA (1988) J Phys Chem 92:1893

15. Nosaka Y, Ohta N, Miyama H (1990) J Phys Chem 94:3752

16. Tang J, Durrant JR, Klug DR (2008) J Am Chem Soc 130:13885

17. Kudo A, Tanaka A, Domen K, Onishi T (1988) J Catal 111:296

18. Baba R, Nakabayashi S, Fujishima A, Honda K (1985) J Phys Chem 89:1902

19. Marković NM, Grgur BN, Ross PN (1997) J Phys Chem B 101:5405

20. Correia AN, Machado SAS (1998) Electrochim Acta 43:367

21. Krishtalik LI (2000) Biochim Biophys Acta 1458:6

22. Krishtalik LI (2001) Electrochim Acta 46:2949

23. Lewis GP, Ruetschi P (1962) J Phys Chem 66:1487

24. Takahashi Y, Oka S, Oikawa M (1958) Bull Chem Soc Jpn 31:220

25. Conway BE, Salomon M (1964) Ber Bunsenges Phys Chem 68:331

26. Rossmeisl J, Qu Z-W, Zhu H, Kroes G-J, Nørskov JK (2007) J Electroanal Chem 607:83

27. Valdés Á, Qu Z-W, Kroes G-J (2008) J Phys Chem C 112:9872

28. Man IC, Su H-Y, Calle-Vallejo F, Hansen HA, Martinez JI, Inoglu NG, Kitchin J, Jaramillo TF, Nørskov JK, Rossmeisl J (2011) ChemCatChem 3:1159

29. Matsumoto Y, Sato E (1986) Mater Chem Phys 14:397

30. Kanan MW, Nocera DG (2008) Science 321:1072 
31. Xiong A, Yoshinaga T, Ikeda T, Takashima M, Hisatomi T, Maeda K, Setoyama T, Teranishi T, Domen K (2014) Eur J Inorg Chem 4:767

32. Abe R, Higashi M, Domen K (2010) J Am Chem Soc 132:11828

33. Bockris JO, Otagawa T (1984) J Electrochem Soc 131:290

34. Suntivich J, May KJ, Gasteiger HA, Goodenough JB, Shao-Horn Y (2011) Science 334:1383

35. Grimaud A, May KJ, Carlton CE, Lee Y-L, Risch M, Hong WT, Zhou J, Shao-Horn Y (2013) Nat Commun 4:2439

36. Sato S, White JM (1980) Chem Phys Lett 72:83

37. Domen K, Naito S, Soma M, Onishi T, Tamaru K (1980) J Chem Soc Chem Commun 543

38. Lehn JM, Sauvage JP, Ziessel R (1980) Nouv J Chim 4:623

39. Domen K, Kudo A, Onishi T (1986) J Catal 102:92

40. Takanabe K, Domen K (2011) Green 1:313

41. Domen K, Naito S, Onishi T, Tamaru K (1982) J Phys Chem $86: 3657$

42. Domen K, Kudo A, Onishi T, Kosugi N, Kuroda H (1986) J Phys Chem 90:292

43. Townsend TK, Browning ND, Osterloh FE (2012) Energy Environ Sci 5:9543

44. Kato H, Asakura K, Kudo A (2003) J Am Chem Soc 125:3082

45. Sakata $Y$, Matsuda $Y$, Nakagawa $T$, Yasunaga R, Imamura $H$, Teramura K (2011) ChemSusChem 4:181

46. Maeda K, Domen K (2007) J Phys Chem C 111:7851

47. Maeda K, Teramura K, Saito N, Inoue Y, Domen K (2006) J Catal 243:303

48. Maeda K, Teramura K, Lu D, Takata T, Saito N, Inoue Y, Domen K (2006) J Phys Chem B 110:13753

49. Maeda K, Teramura K, Masuda H, Takata T, Saito N, Inoue Y, Domen K (2006) J Phys Chem 110:13107
50. Maeda K, Teramura K, Lu D, Saito N, Inoue Y, Domen K (2006) Angew Chem Int Ed 45:7806

51. Yoshida M, Takanabe K, Maeda K, Ishikawa A, Kubota J, Sakata Y, Ikezawa Y, Domen K (2009) J Phys Chem C 113:10151

52. Trasatti S (1972) J Electroanal Chem 32:163

53. Frese KW Jr (1987) Surf Sci 182:85

54. Müller BR, Majoni S, Memming R, Meissner D (1997) Phys Chem B 101:2501

55. Ohno T, Bai L, Hisatomi T, Maeda K, Domen K (2012) J Am Chem Soc 134:8254-8259

56. Maeda K, Lu D, Domen K (2013) Chem Eur J 19:4986

57. Maeda K, Terashima H, Kase K, Higashi M, Tabata M, Domen K (2008) Bull Chem Soc Jpn 81:927

58. Asai R, Nemoto H, Jia Q, Saito K, Iwase A, Kudo A (2014) Chem Commun 50:2543

59. Hisatomi T, Maeda K, Takanabe K, Kubota J, Domen K (2009) J Phys Chem C 113:21458

60. Hisatomi T, Miyazaki K, Takanabe K, Maeda K, Kubota J, Sakata Y, Domen K (2010) Chem Phys Lett 486:144

61. Wrona PK, Lasia A, Lessard M, Ménard H (1992) Electrochim Acta 37:1283

62. Dionigi F, Vesborg PCK, Pedersen T, Hansen O, Dahl S, Xiong A, Maeda K, Domen K, Chorkendorff I (2011) Energy Environ Sci 4:2937

63. Yoshida M, Yamakata A, Takanabe K, Kubota J, Osawa M, Domen K (2009) J Am Chem Soc 131:13218

64. Correia AN, Machado SAS (1998) Electrochim Acta 43:367 